\title{
Novel carbazole-pyridine copolymers by an economical method: synthesis, spectroscopic and thermochemical studies
}

\author{
Aamer Saeed ${ }^{* 1}$, Madiha Irfan ${ }^{1}$ and Shahid Ameen Samra ${ }^{1,2}$
}

\section{Full Research Paper}

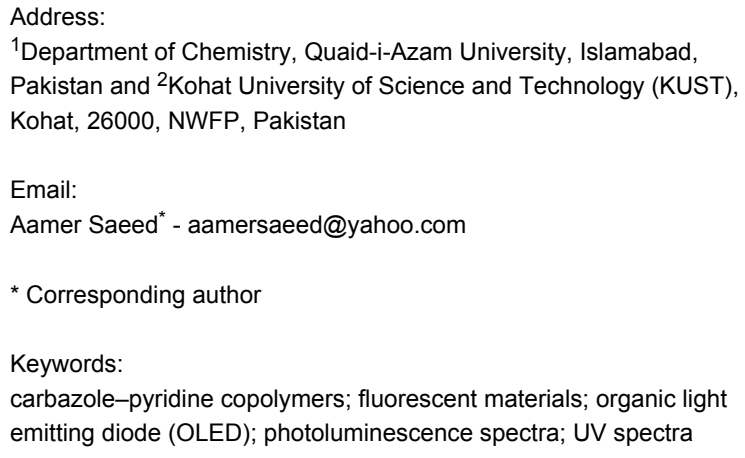

${ }^{1}$ Department of Chemistry, Quaid-i-Azam University, Islamabad, Pakistan and ${ }^{2}$ Kohat University of Science and Technology (KUST), Kohat, 26000, NWFP, Pakistan

Email:

Aamer Saeed* - aamersaeed@yahoo.com

* Corresponding author

Keywords:

carbazole-pyridine copolymers; fluorescent materials; organic light emitting diode (OLED); photoluminescence spectra; UV spectra

\author{
Beilstein J. Org. Chem. 2011, 7, 638-647. \\ doi:10.3762/bjoc.7.75 \\ Received: 02 November 2010 \\ Accepted: 12 April 2011 \\ Published: 19 May 2011 \\ Associate Editor: H. Ritter \\ (C) 2011 Saeed et al; licensee Beilstein-Institut. \\ License and terms: see end of document.
}

\begin{abstract}
The synthesis, as well as spectroscopic and thermochemical studies of a novel class of carbazole-4-phenylpyridine co-polymers are described. The synthesis was carried out by a simple and cheaper method compared to the lengthy methods usually adopted for the preparation of carbazole-pyridine copolymers which involve costly catalysts. Thus, two series of polymers were synthesized by a modified Chichibabin reaction, i.e., by the condensation of diacetylated $N$-alkylcarbazoles with 3-substituted benzaldehydes in the presence of ammonium acetate in refluxing acetic acid. All the polymers were characterized by FTIR, ${ }^{1} \mathrm{H}$ NMR, ${ }^{13} \mathrm{C}$ NMR, UV-vis spectroscopy, fluorimetry, TGA and DSC. The weight average molecular masses $\left(M_{\mathrm{w}}\right)$ of the polymers were estimated by the laser light scattering (LLS) technique.
\end{abstract}

\section{Introduction}

An immense research effort has been focused on organic semiconductors, including polymers, oligomers, dendrimers, small molecules and heavy-metal complexes, after the discovery by Burroughes et al. in 1990 [1-6] that they can be used for fabricating organic light emitting diodes (OLEDs). A number of criteria exist for employing organic materials as LEDs [7] and carbazole containing polymers are the most studied group amongst the different polymers intended for OLED applications [8-15]. Carbazole containing polymers exhibit excellent electron-donating properties together with intense luminescence, high thermal stability and excellent photoconductivity. Furthermore, the functionalization of the carbazole nucleus can easily be carried out at the 3-, 6- and 9-positions to afford a great diversity of structures [16]. Carbazole containing polymers have been greatly explored during the last few years for their applications in organic electronic devices [8]. New conjugated, fully aromatic poly-2,7-carbazole derivatives have been synthesized that exhibit high glass transition temperatures, high 
molecular weights and stability, and that have excellent power efficiency with low bandgaps [17,18]. Alternating poly-2,7carbazole polymers show good thermoelectric properties [19].

Carbazole-pyridine alternate copolymers are a fascinating class of polymers on account of the fact that they take advantage of the combination of the electron-donating properties of carbazole and electron-withdrawing properties of the pyridine ring [20]. Zheng et al. have prepared a new class of copolymers that incorporate pyridine and $N$-alkyl carbazole alternatively into the main chain by oxidative-coupling copolymerization. These polymers are thermostable, highly soluble, and processable, and the fluorescence spectra of the polymers display blue light emitting properties [21].

In view of the above literature reports, it was thought to be of considerable interest to synthesize carbazole-pyridine copolymers by a route that involved the synthesis of the pyridine units as a polymer analogous reaction. To the best of our knowledge, there is no previous report of such a synthesis; the nearest precedent is the use of a Friedländer synthesis to prepare polyquinolines by Jenekhe [22]. Herein, we report a cost-effective synthesis of carbazole-pyridine copolymers in contrast to the protracted and costly methods which involve expensive catalysts.

\section{Results and Discussion}

The synthetic pathway employed to prepare the monomers is outlined in Scheme 1. $N$-Butyl and $N$-octylcarbazoles were synthesized by heating a mixture of carbazole and the respective alkyl halide in a two phase system of aqueous $\mathrm{KOH}(50 \%)$ and benzene in the presence of tetrabutylammonium bromide (TBAB) as a phase-transfer catalyst [23-25]. The $N$-alkylcarbazoles were subsequently subjected to Friedel-Crafts acetyla-

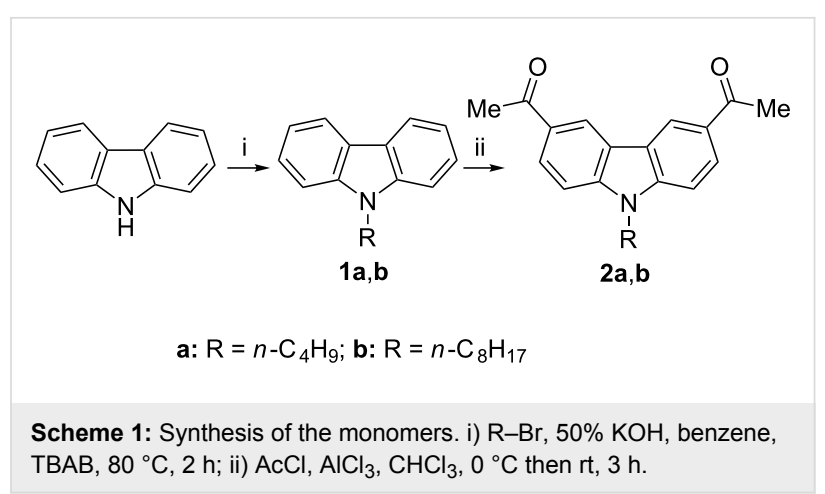

tion at the active positions of carbazole, viz. 3 and 6, with anhydrous aluminum chloride in dry chloroform [26].

The monomers were purified by recrystallization. The diacetylated carbazole monomers were heated under reflux with various 3 -substituted benzaldehydes and ammonium acetate in glacial acetic acid in a modified Chichibabin reaction to assemble the pyridine ring in situ and afford the desired polymers (Scheme 2) [27].

The construction of the pyridine ring in situ by reaction of diacetylated carbazole monomers with different benzaldehydes and ammonium acetate may be envisaged by the complex sequence shown in Scheme 3 which involves protonation, enolization, deprotonation, dehydration, the nucleophilic addition of ammonia, intramolecular cyclization and aromatization.

The polymers were obtained by pouring the reaction mixture into distilled water, followed by filtration and washing of the residue with copious quantities of distilled water to remove completely acetic acid and salts. Finally, the polymers were dissolved in THF and re-precipitated thrice in methanol to

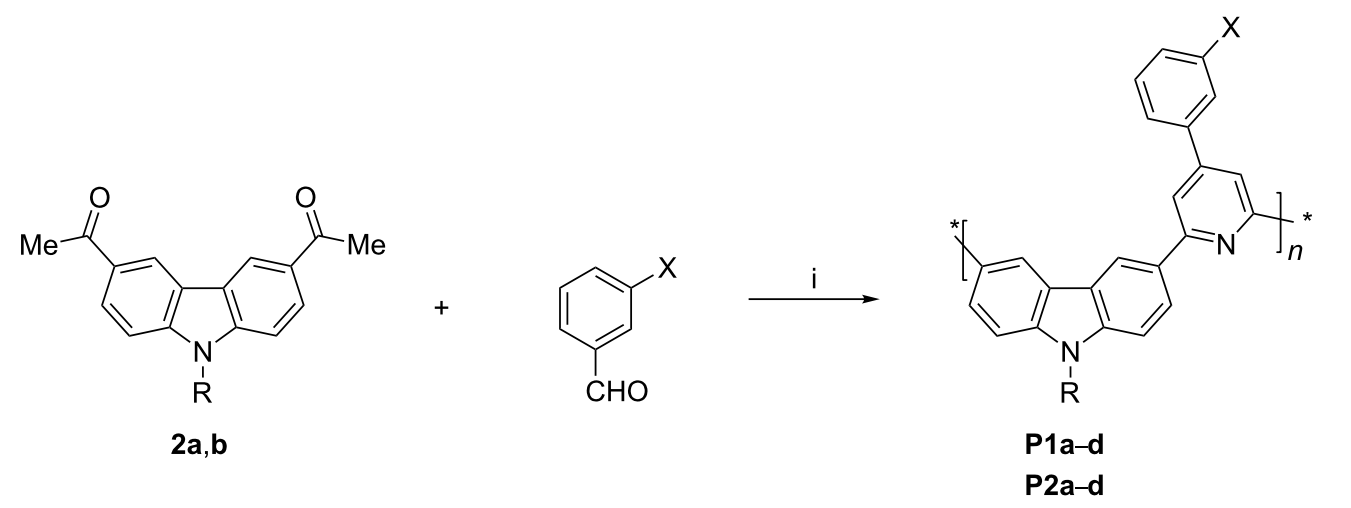

P1: $\mathrm{R}=n-\mathrm{C}_{4} \mathrm{H}_{9} ; \mathrm{a}: \mathrm{X}=\mathrm{H} ; \mathrm{b}: \mathrm{X}=\mathrm{NO}_{2} ; \mathrm{c}: \mathrm{X}=\mathrm{OH} ; \mathrm{d}: \mathrm{X}=\mathrm{Br}$

P2: $\mathrm{R}=n-\mathrm{C}_{8} \mathrm{H}_{17} ; \mathrm{a}: \mathrm{X}=\mathrm{H} ; \mathrm{b}: \mathrm{X}=\mathrm{NO}_{2} ; \mathrm{c}: \mathrm{X}=\mathrm{OH} ; \mathrm{d}: \mathrm{X}=\mathrm{Br}$ 

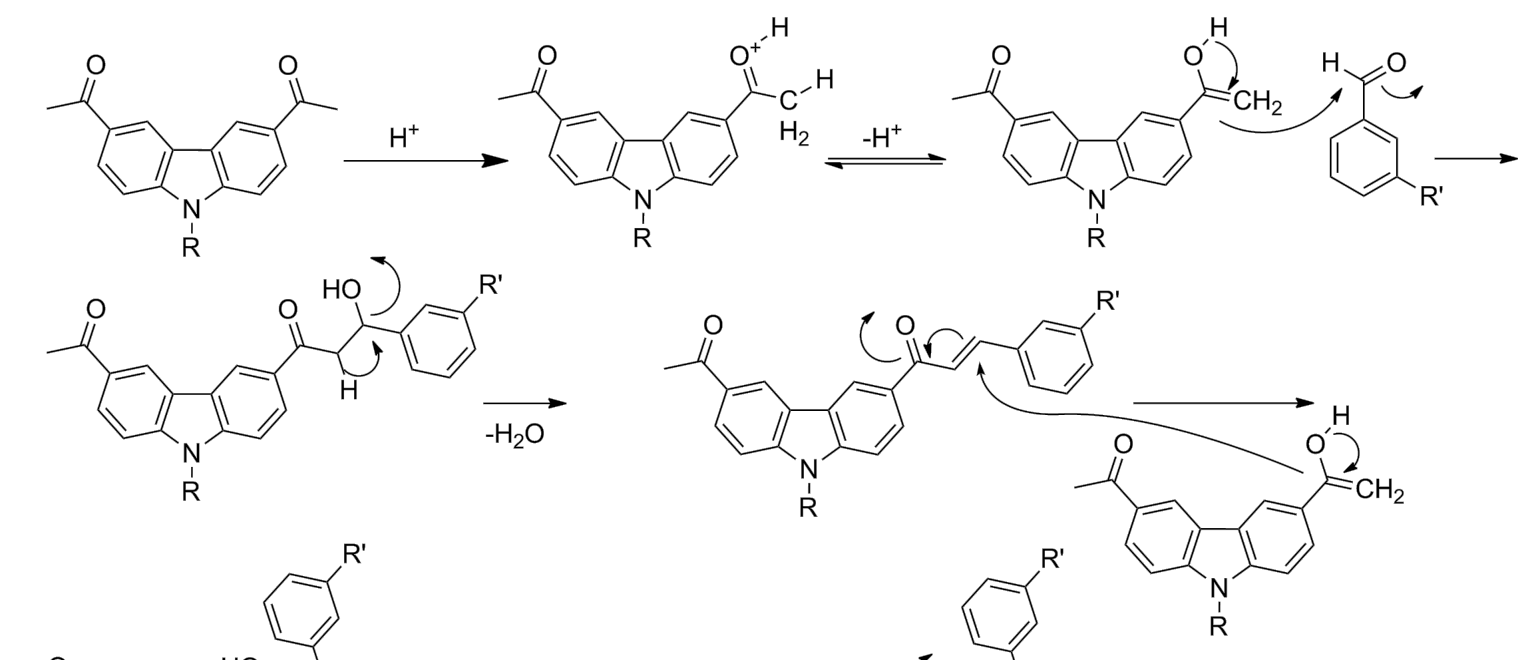

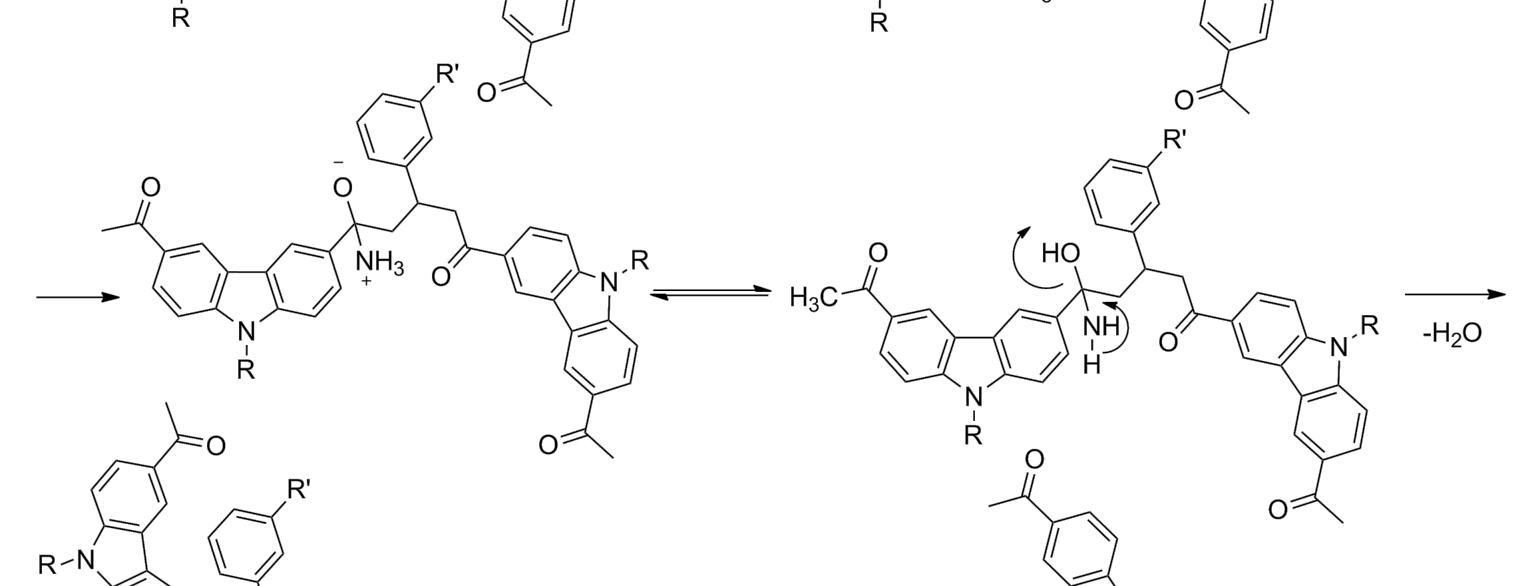

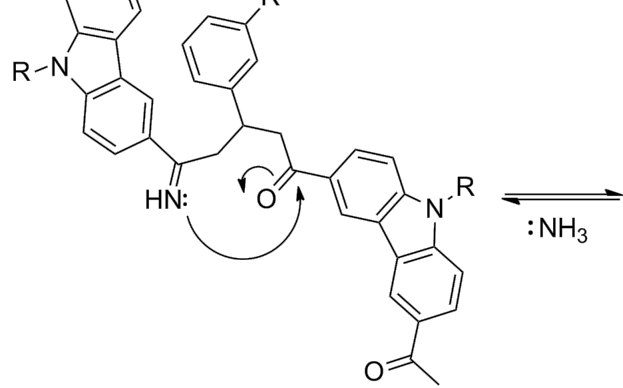<smiles>[R]c1cccc(C2CC(c3ccc4c(c3)c3cc(C(C)=O)ccc3n4[R])=NC(O)(CCC)C(C(=O)c3ccc4c(c3)c3cc(C)ccc3n4[R])C2)c1</smiles><smiles>[R]c1cccc(C2C=C(c3ccc4c(c3)c3cc(C(C)=O)ccc3n4[R])N=C(c3ccc4c(c3)c3cc(C(C)=O)ccc3n4[R])C2)c1</smiles><smiles>[R]c1ccccc1-c1cc(-c2ccc3c(c2)c2cc(C(C)=O)ccc2n3[R])nc(-c2ccc3c(c2)c2cc(C(C)=O)ccc2n3[R])c1</smiles> 
remove oligomers. The polymers were obtained as yellow to brown powders which were then dried in a vacuum oven. The polymers were readily soluble, at room temperature, in a variety of common solvents such as tetrahydrofuran, dichloromethane, chloroform and acetone.

All polymers were characterized on the basis of FTIR, ${ }^{1} \mathrm{H}$ NMR and ${ }^{13} \mathrm{C}$ NMR spectroscopic analysis. The IR spectral data of all polymers showed the characteristic peaks of $\mathrm{C}=\mathrm{N}$ stretching at 1590-1584 $\mathrm{cm}^{-1}$, aromatic tertiary $\mathrm{C}-\mathrm{N}$ stretching at $1354-1340 \mathrm{~cm}^{-1}$, and $\mathrm{C}-\mathrm{N}$ stretching at $1153-1143 \mathrm{~cm}^{-1}$ showing the formation of the pyridine ring. The peaks at 3415 and $1523 \mathrm{~cm}^{-1}$ indicating the presence of $\mathrm{OH}-$ and $\mathrm{NO}_{2}$ - groups respectively, were also observed in the corresponding polymers. Figure $1 \mathrm{~b}$ shows the ${ }^{1} \mathrm{H}$ NMR spectrum of the polymer P1a whilst that of corresponding monomer is shown in Figure 1a.

A comparison of the ${ }^{1} \mathrm{H}$ NMR spectra of the monomer to that of the polymer indicates the disappearance of a peak due to acetyl protons at $\delta 2.75 \mathrm{ppm}$ in addition to the appearance of a number of new peaks in the aromatic region. A complex pattern of splitting in the aromatic region and the characteristic peak broadening was also observed consistent with the in situ formation of the pyridine ring and polymerization. Polymer solutions in THF were subjected to GPC using polystyrene standards for the determination of the molecular weights, however, no elution was observed for any of the polymers. Therefore, molecular weights could not be determined by GPC, because no standard column was found to be compatible with this type of polymer. Consequently, it was decided that the molecular weights would be determined by the LLS technique, and the results are given in Table 1.

In the static laser light scattering (LLS) technique, the angular dependence of the excess absolute time-average scattered intensity, the so-called Raleigh ratio $R_{\mathrm{vv}}(\mathrm{q})$ at a scattering angle $\theta$ is measured. The molecular weights of the polymers in a dilute solution at a concentration $C$ can then be obtained on the basis of the following equation:

$$
\frac{\mathrm{K} C}{R_{\mathrm{vV}}(\mathrm{q})} \cong \frac{1}{M_{\mathrm{w}}}\left(1+\frac{1}{3}\left\langle R_{\mathrm{g}}{ }^{2}\right\rangle \mathrm{q}^{2}\right)+2 \mathrm{~A}_{2} c
$$

where $\mathrm{K}=4 \pi^{2} n^{2}(\mathrm{~d} n / \mathrm{d} C)^{2} /\left(N_{\mathrm{A}} \lambda_{0}{ }^{4}\right), \mathrm{q}=\left(4 \pi n / \lambda_{0}\right) \sin (\theta / 2)$ and $N_{\mathrm{A}}$, $\mathrm{d} n / \mathrm{d} C, n, \lambda_{0}$, and $\theta$ being Avogadro's number, the specific refractive index increment, the solvent refractive index, the wavelength of the light in vacuo, and the scattering angle, respectively. $M_{\mathrm{w}}$ is the weight average molar mass, $\mathrm{A}_{2}$ is the second virial coefficient, and $\left\langle R_{\mathrm{g}}{ }^{2}\right\rangle_{\mathrm{Z}}{ }^{1 / 2}$ is the root-mean square $\mathrm{Z}$-average radius of gyration of the polymer chain.

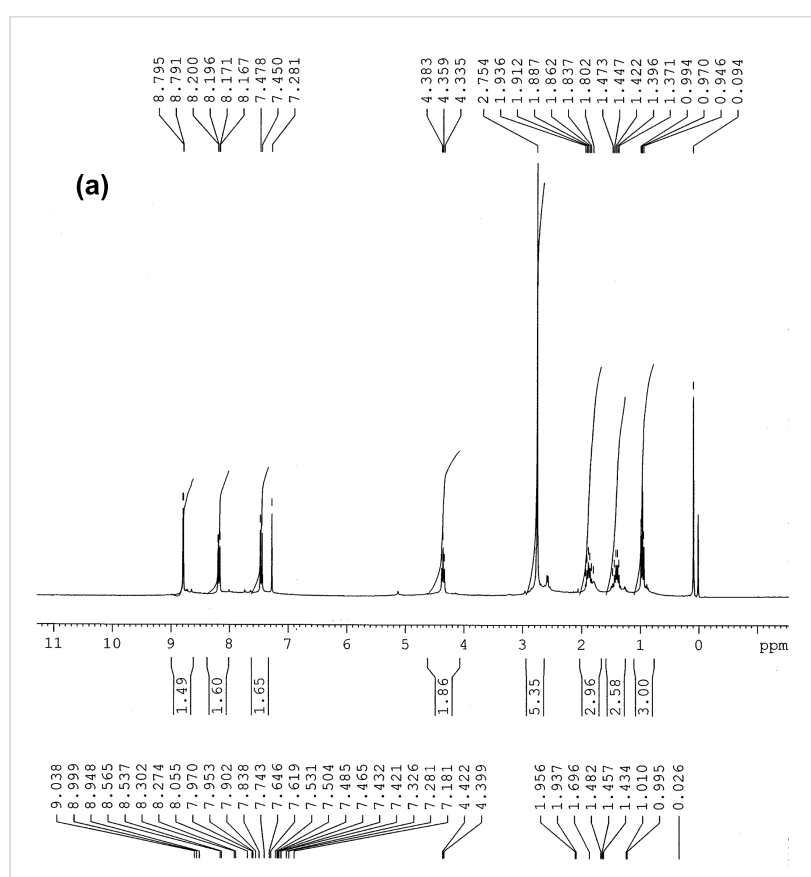

(b)

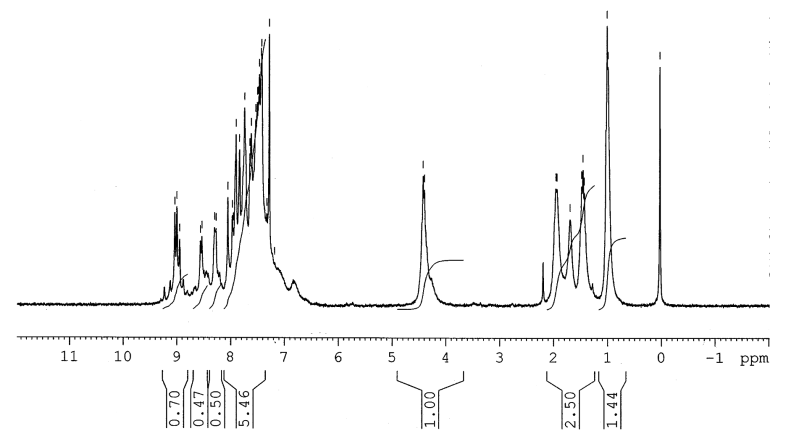

Figure 1: ${ }^{1} \mathrm{H}$ NMR spectra of (a) monomer $2 \mathbf{a}$ and (b) polymer $\mathbf{P} 1 \mathrm{a}$.

By measuring $R_{\mathrm{vv}}(\mathrm{q})$ at a set of $C$ and $\theta, \mathrm{M}_{\mathrm{w}},<R_{\mathrm{g}}>\mathrm{z}$ and $\mathrm{A}_{2}$ can be determined from a conventional Zimm plot which incorporates $\mathrm{q}$ and $C$ extrapolation on a single grid. There are experimental points at all grid points except along the lower line (the $\theta=0$ line) and the left-most line (the $C=0$ ) line. The values of $M_{\mathrm{W}}$ and $\left\langle R_{\mathrm{g}}\right\rangle_{\mathrm{z}}$ were calculated from the slopes of $\left[\mathrm{K} C / R_{\mathrm{Vv}}\right.$ (q) $]_{C \rightarrow 0}$ vs $\mathrm{q}^{2}$ and $\left[\mathrm{KC} / R_{\mathrm{vv}}(\mathrm{q})\right]_{\mathrm{q} \rightarrow 0}$ vs $C$ and the intercept of $\left[\mathrm{K} C / R_{\mathrm{vv}}(\mathrm{q})\right]_{\mathrm{q} \rightarrow 0, C \rightarrow 0}$, respectively. Figure 2 shows the Zimm plot of P2a in THF at room temperature.

\section{Thermochemical properties of the polymers}

The thermal properties of the two series of polymers, P1 and P2 were investigated by thermogravimetric analysis (TGA) and differential scanning calorimetry (DSC). For TGA the samples were heated (PerkinElmer Thermal Analysis System 409) from $25^{\circ} \mathrm{C}$ to $85^{\circ} \mathrm{C}$ at a rate of $10^{\circ} \mathrm{C} / \mathrm{min}$ and at a nitrogen gas flow 


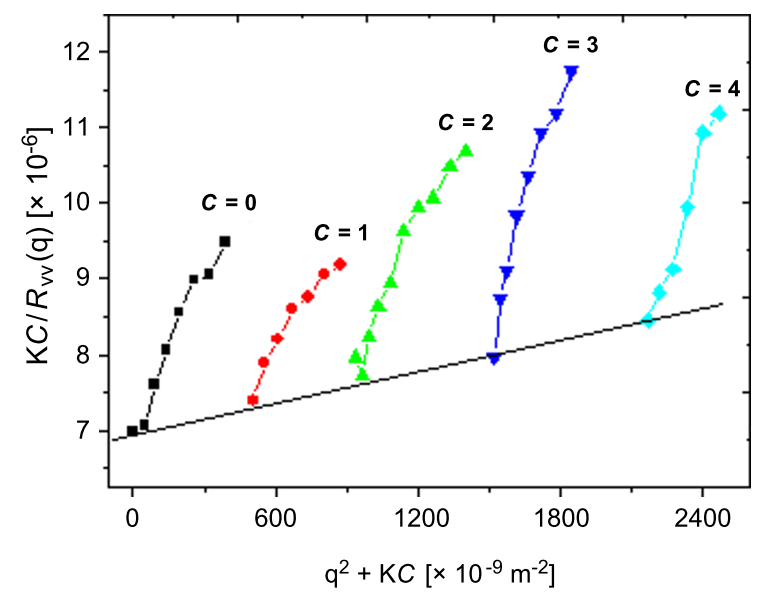

Figure 2: Zimm plot for P2a in THF at room temperature.

rate of $80 \mathrm{~mL} / \mathrm{min}$. Polymers $\mathbf{P 1}$ and $\mathbf{P 2}$ lost weight gradually during the early phase of the experiment. A thermal gravimetric analysis curve of P1a is shown in Figure 3.

The thermal analysis results indicated that polymers P1 and P2 have a high decomposition temperature $T_{\mathrm{d}}$ and good thermal stability above $300{ }^{\circ} \mathrm{C}$, which is very attractive for the fabrication of stable organic electroluminescent devices. TGA thermo-

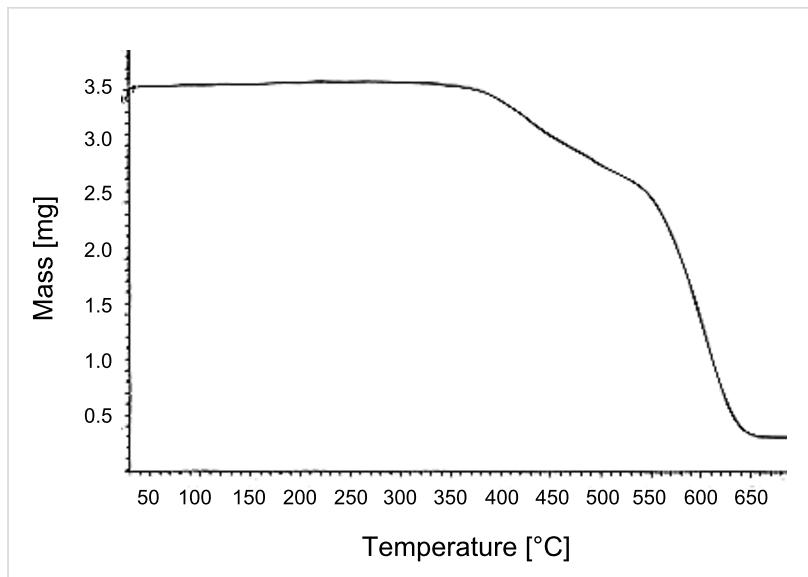

Figure 3: Thermogravimetric analysis curve of $\mathbf{P 1 a}$

grams for polymers $\mathbf{P 1}$ and $\mathbf{P 2}$ are shown in Figure 4 and the results of the thermal analysis are shown in Table 1.

For DSC, the samples were first heated to melting, then cooled to the glassy state and reheated to determine the glass transition temperature $\left(T_{\mathrm{g}}\right)$. A representative DSC graph is shown for P1a in Figure 5. $T_{\mathrm{g}}$ is calculated from the second heating curve. As it can be seen from the graph, $T_{\mathrm{g}}$ for the polymer is $154{ }^{\circ} \mathrm{C}$. All the polymers show glass transition temperatures above $150{ }^{\circ} \mathrm{C}$ (Table 1).

Table 1: Thermal data and molecular weights for polymers P1 and P2.

\begin{tabular}{cccccccc} 
& P1a & P1b & P1c & P1d & P2a & P2b & P2c \\
\hline$\left(M_{\mathrm{w}}\right) 10^{5}(\mathrm{~g} / \mathrm{mol})^{\mathrm{a}}$ & 0.57 & 0.56 & 0.75 & 0.12 & 1.28 & 2.43 & 1.73 \\
$T_{\mathrm{d}}\left({ }^{\circ} \mathrm{C}\right)^{\mathrm{b}}$ & 380 & 300 & 265 & 300 & 376 & 295 & 400 \\
$T_{\mathrm{g}}\left({ }^{\circ} \mathrm{C}\right)^{\mathrm{c}}$ & 154 & 165 & 161 & 170 & 158 & 160 & 158 \\
\hline
\end{tabular}

a Molecular weights of polymers of series $\mathbf{P} 1$ and $\mathbf{P} 2$ by static LLS. ${ }^{\mathrm{b}}$ Decomposition temperature $T_{\mathrm{g}}$ determined by TGA at a heating rate of $10{ }^{\circ} \mathrm{C} / \mathrm{min}$ under a $\mathrm{N}_{2}$ atmosphere. "Glass transition temperature $T_{\mathrm{g}}$ determined by DSC at a heating rate of $10^{\circ} \mathrm{C} / \mathrm{min}$ under a $\mathrm{N}_{2}$ atmosphere, $2^{\text {nd }}$ run.

(a)

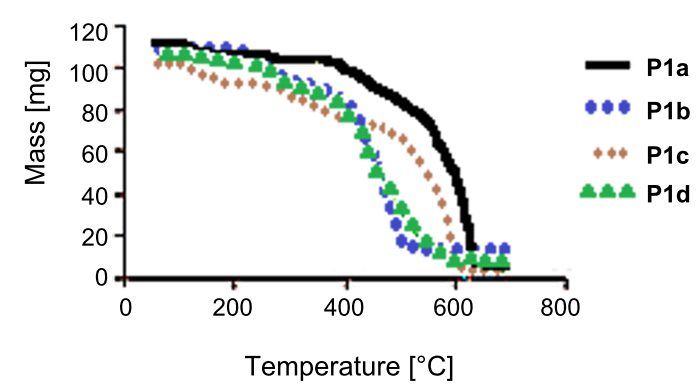

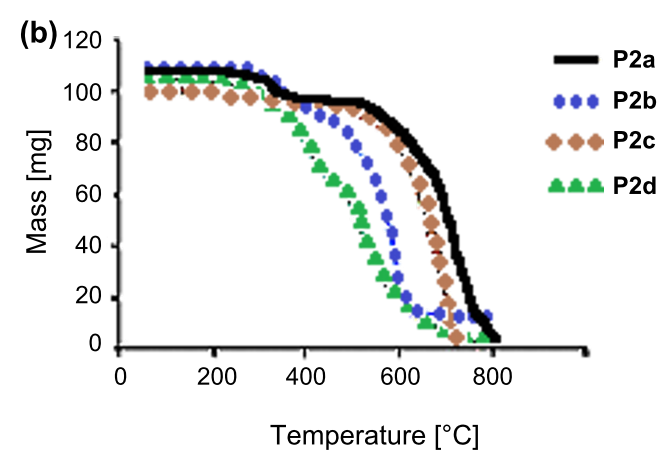

Figure 4: TGA curves of polymers (a) P1 and (b) P2. 


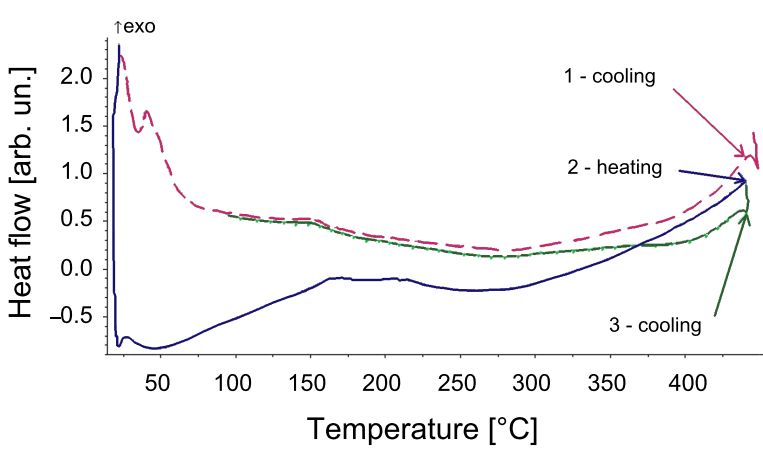

Figure 5: DSC graph for polymer P1a.

\section{Photophysical properties of the polymers}

The photophysical properties of the polymer, including absorption and emission spectral studies, were determined from solutions in chloroform. A summary of the measured spectroscopic data is given in Table 2.

Figure 6 shows the absorption spectra for the two series of polymers. The solution of P1a exhibited an absorption maximum at $301 \mathrm{~nm}$ along with a shoulder at a higher wavelength. Similarly, P1b, P1c and P1d had $\lambda_{\max }$ values of 282, 285 and $300 \mathrm{~nm}$, respectively. Distinct shoulders are observed for all of the four polymers at higher wavelengths. Similar spectra were obtained for polymers of $\mathbf{P 2}$ series. The $\lambda_{\max }$ values were 291, 284, 291 and $289 \mathrm{~nm}$ for P2a, P2b, P2c and P2d, respectively, along with distinct shoulders. The main peaks on the spectra are attributed to a $\pi \rightarrow \pi^{*}$ transition, and the shoulders correspond to $\mathrm{n} \rightarrow \pi^{*}$ transitions in the respective materials. A comparison of the photophysical properties of the synthesized polymers may be made with structurally related polymers previously synthesized by Zheng et al. [21,28]. The observed differences in the absorption spectra of both polymer series arise due to the difference in alkyl chain lengths. As the chain length increases, there is a marked decrease in the bandwidth of the absorption and emission bands [29]. By comparing both series of polymers, the absorption maxima shifts to an upper limit with increasing chain length [30]. Furthermore, polymers with similar groups in both series show similar absorption maxima, but the apparent differences from one another are due to the difference in the electron-donating and electron-withdrawing nature of the substituents. The additional peak in the absorption spectrum of P1c is due to the optical transition attributed to the presence of the auxochromic $\mathrm{OH}$ group, which increases the conjugation length [31] and becomes part of extended chromophore. This effect is absent in the other compounds.

The photoluminescence spectra of the polymer solutions of series $\mathbf{P 1}$ and $\mathbf{P 2}$ in $\mathrm{CHCl}_{3}$ are shown in Figure 7. Polymers P1a, P1b, P1c and P1d show emission maxima at 417, 424, 397 and $421 \mathrm{~nm}$, respectively, whereas polymers P2a, P2b, P2c

\begin{tabular}{|c|c|c|c|c|c|c|c|c|}
\hline & P1a & P1b & P1c & P1d & P2a & $\mathbf{P} 2 \mathrm{~b}$ & P2c & P2d \\
\hline$\lambda_{\text {abs,max }}[\mathrm{nm}]$ & 301 & 282 & 285 & 300 & 291 & 284 & 291 & 289 \\
\hline$\lambda_{\mathrm{em}, \max }[\mathrm{nm}]$ & 417 & 424 & 397 (491) & 421 & 426 & 435 & $400(524)$ & 431 \\
\hline
\end{tabular}
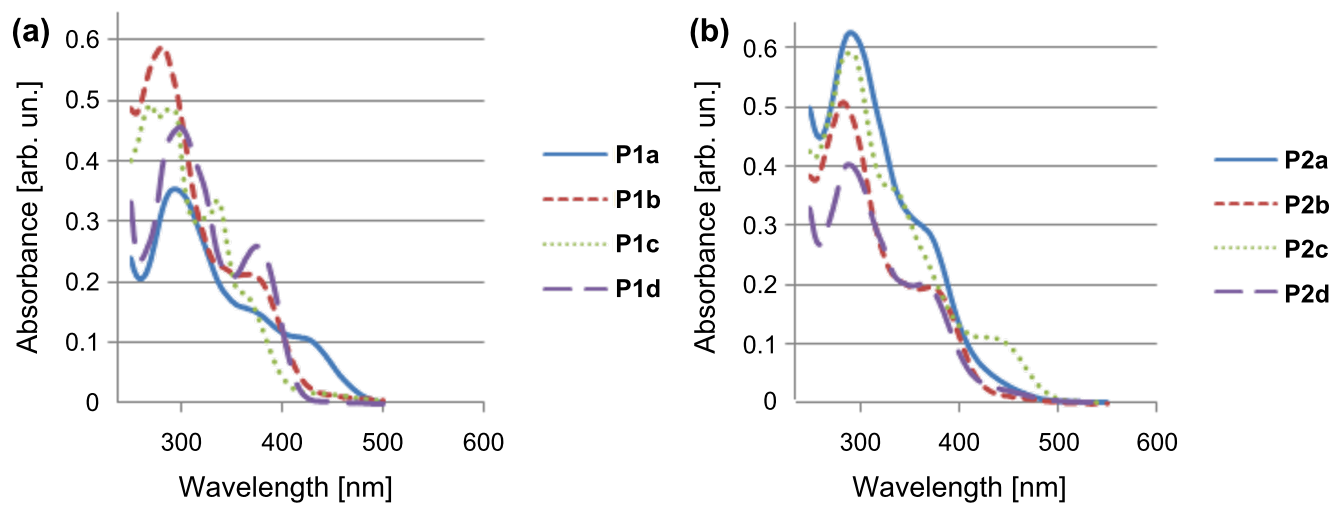

Figure 6: UV-vis spectra of the polymers of (a) series $\mathbf{P} 1$ and (b) series $\mathbf{P 2}$. 

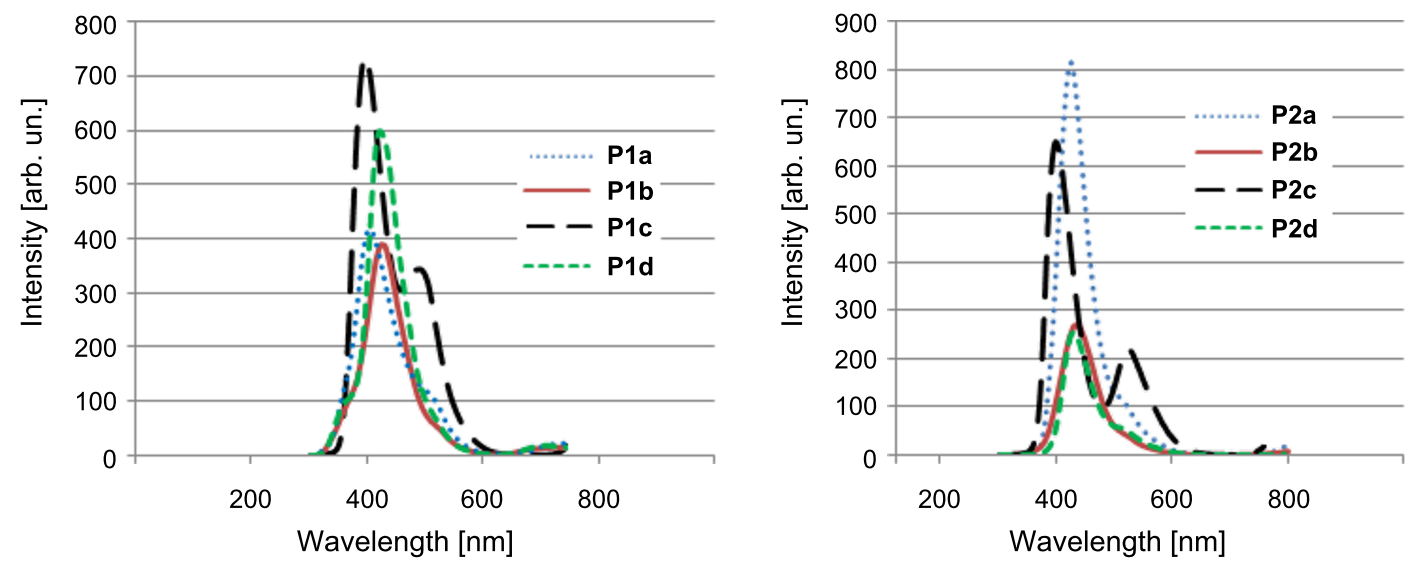

Figure 7: Photoluminescence spectra of polymers $\mathbf{P} 1$ and $\mathbf{P} 2$ in $\mathrm{CHCl}_{3}$ solution.

and P2d show maxima at 426, 435, 400 and $431 \mathrm{~nm}$, respectively. Polymers P1c and P2c having hydroxyl functionality show an extra emission band at 491 and $524 \mathrm{~nm}$, respectively. These suggest that the polymer solutions in $\mathrm{CHCl}_{3}$ should emit blue-green light.

The emission colors of dilute solutions of the polymer samples were also observed under UV light and are shown in Figure 8.

\section{Conclusion}

A new class of polymeric materials that contain alternating hole transporting and electron transporting moieties of carbazole and pyridine, respectively, has been synthesized by a simple and inexpensive method. The polymers are highly soluble in most common solvents, which makes them easily to process by spin coating methods. These materials can be considered as potential candidates for application as OLEDs. The synthesis of further polymers of this novel class is underway.

\section{Experimental}

Melting points were recorded using a digital Gallenkamp (Sanyo) model MPD BM 3.5 apparatus and are uncorrected.
${ }^{1} \mathrm{H}$ and ${ }^{13} \mathrm{C}$ NMR spectra were determined in deuterochloroform solutions using a Bruker AM-300 spectrophotometer. FTIR spectra were recorded on an FTS $3000 \mathrm{MX}$ spectrophotometer. Mass spectra (EI, 70eV) were obtained on a GC-MS instrument of Agilent technologies. UV-vis and fluorescence spectra were recorded on a Perkin Elmer Lambda 20 UV-visible spectrophotometer and a Perkin Elmer LS 55 fluorescence spectrophotometer, respectively.

Molecular weights of the polymers were determined by the laser light scattering (LLS) technique using a commercial light-scattering spectrometer (ALV/SP-150 equipped with an ALV-5000 multi- $\tau$ digital time correlator) with a solid-state laser (ADLAS DPY 425II, output power $\approx 400 \mathrm{~mW}$ at $\lambda=532 \mathrm{~nm}$ ) as the light source. Thermogravimetric analysis (TGA) was performed with a PerkinElmer Thermal analysis System 409. Differential scanning calorimetry (DSC) measurements were performed using Bruker Reflex II thermosystem. The TGA and DSC measurements were recorded under a nitrogen atmosphere at a heating rate of $10{ }^{\circ} \mathrm{C} / \mathrm{min}$. Elemental analyses were performed on CHNS 932 LECO instrument.
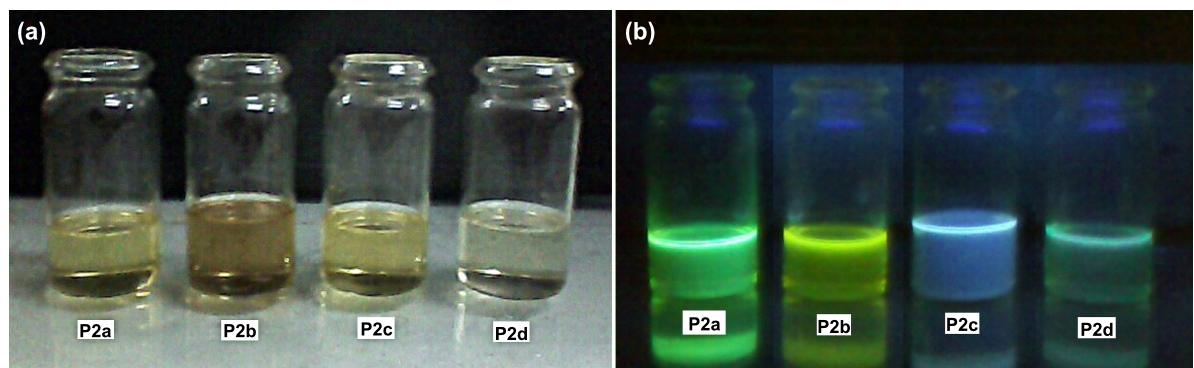

Figure 8: (a) Polymers of $\mathbf{P 2}$ series in visible light; (b) observed fluorescence $\left(\mathrm{CHCl}_{3}\right.$ dilute solutions) under UV irradiation (254 $\left.\mathrm{nm}\right)$. 
Carbazole, 1-bromobutane, 1-bromooctane, tetrabutylammonium bromide (TBAB) and aluminum chloride were commercial products from Fluka; acetyl chloride, benzaldehydes and ammonium acetate were purchased from the Aldrich Chemical Company. Glacial acetic acid was purchased from Riedel de-Haën.

\section{Synthesis of 9-butylcarbazole (1a)}

A mixture of carbazole $(8.35 \mathrm{~g}, 50 \mathrm{mmol}), 1$-bromobutane (7.13 g, $52 \mathrm{mmol})$, benzene $(25 \mathrm{~mL}), 50 \% \mathrm{KOH}$ aqueous solution $(60 \mathrm{~mL})$, tetrabutylammonium bromide (TBAB, $0.4 \mathrm{~g}$, $1.25 \mathrm{mmol}$ ) was stirred at $80{ }^{\circ} \mathrm{C}$ for $2 \mathrm{~h}$. The reaction mixture was cooled to room temperature. The benzene layer was separated, diluted with $20 \mathrm{~mL}$ of ethyl acetate, washed with three $50 \mathrm{~mL}$ portions of water and dried over anhydrous $\mathrm{MgSO}_{4}$. Solvents were removed in vacuo to give a viscous oil, which solidified on standing at room temperature to afford a white solid. Recrystallization from ethanol gave 1a as white needles (92\%). Mp 54-56 ${ }^{\circ} \mathrm{C}$; IR (KBr, v/cm $\left.{ }^{-1}\right): 1640,1350,1153$; ${ }^{1} \mathrm{H}$ NMR $\left(\mathrm{CDCl}_{3}, 300 \mathrm{MHz}\right): \delta 8.16(\mathrm{~d}, J=7.8 \mathrm{~Hz}, 2 \mathrm{H}), 7.51$ (m, 4H), $7.28(\mathrm{~d}, J=7.6 \mathrm{~Hz}, 2 \mathrm{H}), 4.35(\mathrm{t}, J=7.2 \mathrm{~Hz}, 2 \mathrm{H}), 1.90$ $(\mathrm{m}, 2 \mathrm{H}), 1.45(\mathrm{~m}, 2 \mathrm{H}), 0.99(\mathrm{t}, J=7.2 \mathrm{~Hz}, 3 \mathrm{H}) ;{ }^{13} \mathrm{C} \mathrm{NMR}$ $\left(\mathrm{CDCl}_{3}, 75 \mathrm{MHz}\right): \delta 140.7,125.5,122.8,120.3,118.7,108.6$, 42.8, 31.17, 20.62, 13.95; Elemental analysis: Calcd C: $86.0 \%$, H: $7.6 \%$, N: $6.2 \%$; found C: $85.8 \%$, H: $7.5 \%$, N: $6.1 \%$.

\section{9-Octylcarbazole (1b)}

The compound $\mathbf{1 b}$ was synthesized by the same procedure as for 1a using carbazole (8.35 g, $50 \mathrm{mmol}), 1$-bromooctane $(10.0 \mathrm{~g}, 52 \mathrm{mmol})$, benzene $(25 \mathrm{~mL})$, and TBAB $(0.4 \mathrm{~g}$, $1.25 \mathrm{mmol})$. The product was obtained as a light-yellow oil (87\%). IR ( $\mathrm{NaCl}$ cell, v/cm $\left.{ }^{-1}\right): 1630,1340,1147 ;{ }^{1} \mathrm{H}$ NMR $\left(\mathrm{CDCl}_{3}, 300 \mathrm{MHz}\right): \delta 8.35(\mathrm{~d}, J=7.8 \mathrm{~Hz}, 2 \mathrm{H}), 7.69(\mathrm{~m}, 4 \mathrm{H})$, $7.59(\mathrm{~d}, J=8.1 \mathrm{~Hz}, 2 \mathrm{H}), 4.41(\mathrm{t}, J=7.2 \mathrm{~Hz}, 2 \mathrm{H}), 2.03(\mathrm{~m}, 2 \mathrm{H})$, $1.51(\mathrm{~m}, 5 \mathrm{H}), 1.14(\mathrm{t}, J=7.2 \mathrm{~Hz}, 3 \mathrm{H}) ;{ }^{13} \mathrm{C} \mathrm{NMR}\left(\mathrm{CDCl}_{3}\right.$, $75 \mathrm{MHz}$ ): $\delta$ 140.5, 125.8, 123.0, 120.5, 118.9, 108.9, 43.1, 32.1, 29.6, 29.4, 29.2 27.5, 22.9, 14.4; Elemental analysis: Calcd C: $85.9 \%$, H: $9.0 \%$, N: $5.0 \%$; found C: $85.8 \%, \mathrm{H}: 8.9 \%$, N: $5.0 \%$.

\section{3,6-Diacetyl-9-butylcarbazole (2a)}

Aluminum chloride, (4.0 g, $3 \mathrm{mmol})$ and acetyl chloride, ( $2.35 \mathrm{~g}, 3 \mathrm{mmol}$ ) were added successively to $10 \mathrm{~mL}$ of dry chloroform. The mixture was stirred for $10 \mathrm{~min}$ at $0{ }^{\circ} \mathrm{C}$ to obtain a clear solution. A solution of $(4.46 \mathrm{~g}, 2 \mathrm{mmol})$ of $1 \mathrm{a}$ in $10 \mathrm{~mL}$ of dry chloroform was added dropwise to the above solution at $0{ }^{\circ} \mathrm{C}$ during $15 \mathrm{~min}$. The reaction mixture was stirred at room temperature for $3 \mathrm{~h}$. After the completion of the reaction (TLC monitoring), the reaction mixture was poured into a stirred solution of $10 \% \mathrm{HCl}(50 \mathrm{~mL})$. The organic layer was separated, washed with distilled water three times and dried over anhydrous $\mathrm{Na}_{2} \mathrm{SO}_{4}$. The solvent was removed in vacuo to give a solid which was recrystallized from ethanol to afford 2a (85\%) as dull green crystals with a moldy bread smell. Mp $145^{\circ} \mathrm{C}$; IR $\left(\mathrm{KBr}, \mathrm{v} / \mathrm{cm}^{-1}\right): 2907,1718,1655,1348,1145 ;{ }^{1} \mathrm{H}$ NMR $\left(\mathrm{CDCl}_{3}, 300 \mathrm{MHz}\right): \delta 8.79(\mathrm{~s}, 2 \mathrm{H}), 8.18(\mathrm{dd}, J=8.7 \mathrm{~Hz}, 2 \mathrm{H})$, $7.45(\mathrm{~d}, J=8.4 \mathrm{~Hz}, 2 \mathrm{H}), 4.35(\mathrm{t}, J=7.2 \mathrm{~Hz}, 2 \mathrm{H}), 2.75(\mathrm{~s}, 6 \mathrm{H})$, $1.87(\mathrm{~m}, 2 \mathrm{H}), 1.42(\mathrm{~m}, 2 \mathrm{H}), 0.97(\mathrm{t}, J=7.2 \mathrm{~Hz}, 3 \mathrm{H}) ;{ }^{13} \mathrm{C} \mathrm{NMR}$ $\left(\mathrm{CDCl}_{3}, 75 \mathrm{MHz}\right): \delta 197.4,143.9,129.6,127.0,122.8,122.0$, 108.9, 43.3, 31.0, 26.6, 20.4, 13.8; GC-MS (m/z): $307\left(\mathrm{M}^{+}\right)$, $264(100 \%), 221,178,43,29$.

\section{3,6-Diacetyl-9-octylcarbazole (2b)}

The compound $\mathbf{1 b}$ was synthesized by the same procedure as for 2a from $\mathrm{AlCl}_{3}, 4.00 \mathrm{~g}$ ( $\left.3 \mathrm{mmol}\right)$, acetyl chloride, $2.35 \mathrm{~g}$ ( $3 \mathrm{mmol})$ to afford $\mathbf{1 b} 5.58 \mathrm{~g}(2 \mathrm{mmol})$ in $88 \%$ yield as dull green crystals. $\mathrm{Mp} 139^{\circ} \mathrm{C}$; IR $\left(\mathrm{KBr}, \mathrm{v} / \mathrm{cm}^{-1}\right): 2939,1715,1640$, 1350, 1140; ${ }^{1} \mathrm{H} \mathrm{NMR}\left(\mathrm{CDCl}_{3}, 300 \mathrm{MHz}\right): \delta 8.75(\mathrm{~s}, 2 \mathrm{H}$, Ar-1,1'), 8.18 (dd, 2H, $\left.J=8.4 \mathrm{~Hz}, \mathrm{Ar}-2,2^{\prime}\right), 7.45$ (d, 2H, $J=$ $8.7 \mathrm{~Hz}, \mathrm{Ar}-3,3$ ') 4.34 (t, 2H, $J=7.2 \mathrm{~Hz}, \mathrm{H}-\mathrm{a}), 2.75$ (s, 6H, $\left.\mathrm{COCH}_{3}\right), 1.86$ (m, 2H, H-b), 1.30 (m, 10H, H-c,d,e,f,g), 0.86 (t, $3 \mathrm{H}, J=6.9 \mathrm{~Hz}, \mathrm{H}-\mathrm{h}) ;{ }^{13} \mathrm{C} \mathrm{NMR}\left(\mathrm{CDCl}_{3}, 75 \mathrm{MHz}\right): \delta 198.1$, 142.4, 128.9, 127.0, 121.8, 120.3, 109.9, 43.1, 31.0, 29.3, 28.9, 27.2, 22.4, 13.8; GC-MS (m/z): $363\left(\mathrm{M}^{+}\right), 264(100 \%), 348$, $221,178,43,29$.

\section{General procedure for the synthesis of polymers P1 and P2 (a-d)}

Ammonium acetate $(10 \mathrm{mmol})$ was added portionwise to a stirred equimolar mixture of 3,6-diacetyl- $N$-alkylcarbazole and benzaldehyde in acetic acid $(10 \mathrm{~mL})$. The reaction mixture was heated under reflux for $18 \mathrm{~h}$. Upon completion of reaction (TLC monitoring), the reaction mixture was cooled to room temperature, poured into distilled water $(20 \mathrm{~mL})$ and stirred for $5 \mathrm{~min}$. The precipitated solid was filtered and washed well with copious quantities of distilled water to remove acetic acid and salts completely. The resulting solid was dissolved in THF and precipitated by adding methanol to remove the oligomers. The precipitation process was repeated three times and the polymers obtained were dried in a vacuum oven at $70{ }^{\circ} \mathrm{C}$ overnight.

\section{Poly\{[N-butylcarbazole-3,6-diyl][4-phenylpyridine- 2,6-diyl]\} (P1a)}

Yellow solid; yield: 44\%; IR (KBr, v/ $\left.\mathrm{cm}^{-1}\right)$ : 3055, 2930, 2860, 1658, 1584, 1326, 1153; ${ }^{1} \mathrm{H} \mathrm{NMR}\left(\mathrm{CDCl}_{3}, 300 \mathrm{MHz}\right): \delta 8.94$ (s, Ar-1), 8.55 (dd, $J=8.4 \mathrm{~Hz}, \operatorname{Ar}-2), 8.28$ (d, $J=8.4 \mathrm{~Hz}$, Ar-H), 8.0-7.5 (m, Ar H), 4.4 (t, 2H, J=6.9 Hz, H-a), 1.7 (m, $4 \mathrm{H}, \mathrm{H}-\mathrm{b}, \mathrm{c}), 1.0$ (t, 3H, $J=6.9 \mathrm{~Hz}, \mathrm{H}-\mathrm{d}) ;{ }^{13} \mathrm{C} \mathrm{NMR}\left(\mathrm{CDCl}_{3}\right.$, $75 \mathrm{MHz}): \delta 148.6,146.2,144.1,142.3,139.8,137.2,129.0$, $128.7,127.5,120.5,119.1,116.7,109.5,33.2,29.9,29.2,28.7$, 27.2, 21.9, 14.8; Elemental analysis: Calcd C: $86.6 \%$, H: 5.8\%, $\mathrm{N}: 7.4 \%$; found C: $84.3 \%, \mathrm{H}: 5.9 \%$, N: $7.1 \%$. 


\section{Poly $\{[N$-butylcarbazole-3,6-diyl][4-(3-nitrophenyl)- pyridine-2,6-diyl]\} (P1b)}

Yellow powder; yield: 49\%; IR $\left(\mathrm{KBr}, \mathrm{v} / \mathrm{cm}^{-1}\right)$ : 3035, 2930, 2890, 1656, 1585, 1523, 1345, 1145, 800; ${ }^{1} \mathrm{H} \mathrm{NMR}\left(\mathrm{CDCl}_{3}\right.$, $300 \mathrm{MHz}$ ): $\delta 8.96$ (s, Ar-8), 8.58 (s, Ar-7), 8.27 (m, Ar-H), 8.0 (d, $J=7.8 \mathrm{~Hz}, \operatorname{Ar}-5), 7.92$ (s, Ar-4), 7.66 (d, $J=8.1 \mathrm{~Hz}, \operatorname{Ar}-3)$, 7.54 (m, Ar-H), 4.4 (t, 2H, J=7.1 Hz, H-d), 1.9 (m, 2H, H-c), 1.46 (m, 2H, H-b), 1.0 (t, 3H, $J=7.2 \mathrm{~Hz}, \mathrm{H}-\mathrm{a}) ;{ }^{13} \mathrm{C}$ NMR $\left(\mathrm{CDCl}_{3}, 75 \mathrm{MHz}\right): \delta 148.9,144.5,142.0,137.1,134.3,130.5$, 130.0, 127.8, 124.9, 124.5, 123.3, 122.1, 108.7, 33.5, 29.3, 27.6, 22.6, 14.8; Elemental analysis: Calcd C: $77.3 \%, \mathrm{H}: 5.0 \%, \mathrm{~N}$ : $10.0 \%$; found $\mathrm{C}: 76.9 \%, \mathrm{H}: 4.7 \%, \mathrm{~N}: 9.8 \%$.

\section{Poly\{[N-butylcarbazole-3,6-diyl][4-(3-hydroxy- phenyl)pyridine-2,6-diyl]\} (P1c)}

Dark brown powder; yield: $40 \%$; IR $\left(\mathrm{KBr}, \mathrm{v} / \mathrm{cm}^{-1}\right)$ : 3415,3110 , 2955, 2860, 1663, 1584, 1354, 1146; ${ }^{1} \mathrm{H}$ NMR $\left(\mathrm{CDCl}_{3}, 300\right.$ $\mathrm{MHz}): \delta 8.79(\mathrm{~s}, \mathrm{Ar}-1), 8.21(\mathrm{dd}, J=1.9,9.0 \mathrm{~Hz}, \mathrm{Ar}-2)$, 7.47-7.41 (m, Ar-H), 7.31-7.18 (m, Ar-H), 7.02-6.99 (m, Ar-H), 5.10 (s, OH), 4.34 (t, 2H, $J=9.0 \mathrm{~Hz}, \mathrm{H}-\mathrm{a}), 1.93-1.79$ (m, 2H, H-b), 1.44-1.35 (m, 2H, H-c), 0.97 (t, 3H, $J=9.0 \mathrm{~Hz}$, $\mathrm{H}-\mathrm{d}) ;{ }^{13} \mathrm{C} \mathrm{NMR}\left(\mathrm{CDCl}_{3}, 75 \mathrm{MHz}\right): \delta 150.1,147.1,144.3$, 141.6, 139.7, 137.8, 134.4, 131.1, 129.3, 126.2, 125.4, 122.9, 120.4, 117.1, 109.3, 36.2, 29.3, 28.5, 28.1, 25.5, 22.2, 14.6; Elemental analysis: Calcd C: $83.0 \%, \mathrm{H}: 5.6 \%, \mathrm{~N}: 7.1 \%$; found C: $82.6 \%, \mathrm{H}: 5.3 \%, \mathrm{~N}: 6.8 \%$.

\section{Poly\{[N-butylcarbazole-3,6-diyl][4-(3-bromophenyl)- pyridine-2,6-diyl]\} (P1d)}

Yellow precipitate; yield: $66 \% ; R_{\mathrm{f}}: 0.45 ; \mathrm{IR}\left(\mathrm{KBr}, \mathrm{v} / \mathrm{cm}^{-1}\right)$ : 3065, 2960, 2890, 1652, 1596, 1340, 1143, 664; ${ }^{1} \mathrm{H}$ NMR $\left(\mathrm{CDCl}_{3}, 300 \mathrm{MHz}\right): \delta 8.91(\mathrm{~s}, \mathrm{Ar}-1), 8.28(\mathrm{dd}, J=8.7 \mathrm{~Hz}$, Ar-2), 7.78 (d, $J=4.2 \mathrm{~Hz}, \operatorname{Ar}-\mathrm{H}), 7.55$ (m, Ar-H), 7.33 (at, Ar-H), 4.38 (t, 2H, J=7.2 Hz, H-a), 1.91 (m, 2H, H-b), 1.42 (m, 2H, H-c), 0.98 (t, 3H, $J=7.2 \mathrm{~Hz}, \mathrm{H}-\mathrm{d}) ;{ }^{13} \mathrm{C} \mathrm{NMR}\left(\mathrm{CDCl}_{3}\right.$, $75 \mathrm{MHz}): \delta$ 145.6, 143.2, 136.5, 134.1, 133.7, 131.4, 130.5, 130.3, 127.5, 126.2 123.2, 123.0, 122.6, 109.1, 32.7, 29.1, 27.3, 22.4, 14.8; Elemental analysis: Calcd C: $71.5 \%, \mathrm{H}: 4.6 \%, \mathrm{~N}$ : $6.1 \%$; found C: $69.3 \%, \mathrm{H}: 4.3 \%, \mathrm{~N}: 6.0 \%$.

\section{Poly\{[N-octylcarbazole-3,6-diyl][4-phenylpyridine- 2,6-diyl]\} (P2a)}

Yellow powder; yield: $39 \%$; IR $\left(\mathrm{KBr}, \mathrm{v} / \mathrm{cm}^{-1}\right)$ : 3060, 2950, 2862, 1651, 1590, 1326, 1145; ${ }^{1} \mathrm{H}$ NMR $\left(\mathrm{CDCl}_{3}, 300 \mathrm{MHz}\right)$ : $\delta 8.94$ (s, Ar-1), 8.54-7.47 (m, Ar Hs), 4.38 (t, 2H, H-a), 1.93 (m, 2H, H-b), 1.27 (m, 10H, H-c,d,e,f,g), 0.88 (t, 3H, H-h); ${ }^{13} \mathrm{C}$ NMR $\left(\mathrm{CDCl}_{3}, 75 \mathrm{MHz}\right): \delta 150.6,148.3,147.1,144.4$, 139.8, 136.5, 129.0, 127.3, 126.2, 120.7, 118.1, 116.5, 110.5, 35.2, 30.1, 29.2, 28.7, 27.2, 21.9, 14.8; Elemental analysis: Calcd C: $86.5 \%$, H: $6.9 \%$, N: $6.5 \%$; found C: $83.3 \%$, H: $6.7 \%$, $\mathrm{N}: 6.1 \%$.

\section{Poly\{[N-octylcarbazole-3,6-diyl][4-(3-nitrophenyl)- pyridine-2,6-diyl]\} (P2b)}

Yellow powder; yield: $46 \%$; IR (KBr, $\left.\mathrm{v} / \mathrm{cm}^{-1}\right)$ : 3070,2950 , 2840, 1654, 1586, 1345, 1145, 802; ${ }^{1} \mathrm{H}$ NMR $\left(\mathrm{CDCl}_{3}, 300\right.$ MHz): $\delta 8.96$ (s, Ar-8), 8.58 (s, Ar-7), 8.33-8.22 (m, Ar-H), 8.0 (d, $J=7.8 \mathrm{~Hz}, \mathrm{Ar}-\mathrm{H}), 7.92$ (s, Ar-H), 7.66 (at, Ar-H), 7.5 (d, $J=$ $8.7 \mathrm{~Hz}, \mathrm{Ar}-\mathrm{H}), 4.4(\mathrm{t}, 2 \mathrm{H}, J=6.9 \mathrm{~Hz}, \mathrm{H}-\mathrm{a}), 1.93(\mathrm{~m}, 12 \mathrm{H}$, $\mathrm{H}-\mathrm{b}, \mathrm{c}, \mathrm{d}, \mathrm{e}, \mathrm{f}, \mathrm{g}), 0.86$ (t, $3 \mathrm{H}, J=6.9 \mathrm{~Hz}, \mathrm{H}-\mathrm{h}) ;{ }^{13} \mathrm{C}$ NMR $\left(\mathrm{CDCl}_{3}\right.$, $75 \mathrm{MHz}): \delta 148.7,144.1,141.0,136.9,134.3,130.1,130.0$, 127.6, 124.6, 124.5, 123.1, 122.4, 109.5, 31.7, 29.3, 29.1, 28.4, 27.2, 22.6, 14.0; Elemental analysis: Calcd C: 78.3\%, H: 6.1\%, N: $8.8 \%$; found C: $77.1 \%$, H: $5.9 \%$, N: $8.2 \%$.

\section{Poly\{[N-octylcarbazole-3,6-diyl][4-(3-hydroxy- phenyl)pyridine-2,6-diyl]\} (P2c)}

Brownish-black solid; yield: $42 \%$; IR $\left(\mathrm{KBr}, \mathrm{v} / \mathrm{cm}^{-1}\right)$ : 3345 , 3085, 2925, 2840, 1640, 1589, 1350, 1152; ${ }^{1} \mathrm{H}$ NMR $\left(\mathrm{CDCl}_{3}\right.$, $300 \mathrm{MHz}): \delta 8.94(\mathrm{~s}, \mathrm{Ar}-\mathrm{H}), 8.89(\mathrm{~m}, \mathrm{Ar}-\mathrm{H}), 8.84-8.81(\mathrm{~m}$, Ar-H), 8.22-8.17 (m, Ar-H), 7.49-7.46 (m, Ar-H), 5.31 (s, $\mathrm{OH}), 4.36(\mathrm{t}, 2 \mathrm{H}, J=7.1 \mathrm{~Hz}, \mathrm{H}-\mathrm{a}), 2.20(\mathrm{~m}, 2 \mathrm{H}, \mathrm{H}-\mathrm{b})$, 1.45-1.34 (m, 10H, H-c,d,e,f,g), 0.87 (t, $3 \mathrm{H}, J=7.2 \mathrm{~Hz}, \mathrm{H}-\mathrm{h}$ ); ${ }^{13} \mathrm{C}$ NMR $\left(\mathrm{CDCl}_{3}, 75 \mathrm{MHz}\right): \delta 153.1,145.2,144.3,141.1$, 139.0, 137.2, 134.4, 132.1, 129.3, 127.2, 125.3, 122.6, 120.2, 117.3, 108.2, 39.2, 29.4, 28.6, 28.2, 26.3, 22.5, 15.1; Elemental analysis: Calcd C: $83.4 \%, \mathrm{H}: 6.7 \%$, N: $6.2 \%$; found C: $82.1 \%$, H: $6.4 \%, \mathrm{~N}: 6.0 \%$.

\section{Poly\{[N-octylcarbazole-3,6-diyl][4-(3-bromophenyl)- pyridine-2,6-diyl]\} (P2d)}

Dark yellow precipitates; yield: $40 \%$; $R_{\mathrm{f}}$ : 0.47 ; $\mathrm{IR}(\mathrm{KBr}$, v/ $\mathrm{cm}^{-1}$ ): 3020, 2960, 2855, 1651, 1587, 1343, 1144, 668; ${ }^{1} \mathrm{H} \mathrm{NMR}\left(\mathrm{CDCl}_{3}, 300 \mathrm{MHz}\right): \delta 8.92(\mathrm{~s}, \mathrm{Ar}-1), 8.28(\mathrm{~d}, J=$ $7.5 \mathrm{~Hz}, \mathrm{Ar}-\mathrm{H}), 7.92-7.88$ (m, Ar-H), 7.63-7.49 (m, Ar-H), 7.33 (at, Ar-H), 4.37 (t, 2H, $J=6.6 \mathrm{~Hz}, \mathrm{H}-\mathrm{a}), 1.92$ (m, 2H, H-b), 1.36-1.26 (m, 10H, H-c,d,e,f,g), 0.87 (t, $3 \mathrm{H}, J=6.9 \mathrm{~Hz}, \mathrm{H}-\mathrm{h})$; ${ }^{13} \mathrm{C}$ NMR $\left(\mathrm{CDCl}_{3}, 75 \mathrm{MHz}\right): \delta 144.0,142.2,137.2,133.1$, 130.8, 130.4, 130.4, 130.3, 127.5, 127.3, 123.2, 123.1, 123.0, 122.2, 109.3, 31.7, 29.3, 29.1, 28.9, 27.3, 22.6, 14.1; Elemental analysis: Calcd C: $73 \%, \mathrm{H}: 5.6 \%$, N: $5.5 \%$; found C: $70 \%, \mathrm{H}$ : $5.4 \%, \mathrm{~N}: 5.2 \%$.

\section{Acknowledgements}

The authors gratefully acknowledge a research grant from Quaid-i-Azam University, Islamabad, under the URF program. M. I. gratefully acknowledges a research scholarship from HEC, Islamabad, under the HEC Indigenous PhD Scholarship 5000 Scheme. 


\section{References}

1. Burroughes, J. H.; Bradley, D. D. C.; Brown, A. R.; Marks, R. N.; Mackay, K.; Friend, R. H.; Burns, P. L.; Holmes, A. B. Nature 1990, 347, 539. doi:10.1038/347539a0

2. Morin, J. F.; Beaupré, S.; Leclerc, M.; Lévesque, I.; D’lorio, M. Appl. Phys. Lett. 2002, 80, 341. doi:10.1063/1.1433917

3. Grimsdale, A. C.; Chan, K. L.; Martin, R. E.; Jokisz, P. G.; Holmes, A. B. Chem. Rev. 2009, 109, 897. doi:10.1021/cr000013v

4. Winder, C.; Sariciftci, N. S. J. Mater. Chem. 2004, 14, 1077. doi:10.1039/b306630d

5. Frampton, M. J.; Namdas, E. B.; Lo, S. C.; Burn, P. L.; Samuel, I. D. W. J. Mater. Chem. 2004, 14, 2881. doi:10.1039/b400160e

6. Zhang, X.; Yang, C.; Chen, L.; Zhang, K.; Qin, J. Chem. Lett. 2006, 35, 72. doi:10.1246/cl.2006.72

7. Forrest, S. R. Org. Electron. 2003, 4, 45. doi:10.1016/j.orgel.2003.08.014

8. Grigalevicius, S.; Simokaitiene, J.; Grazulevicius, J. V.; Ma, L.; Xie, Z. Synth. Met. 2008, 158, 739. doi:10.1016/j.synthmet.2008.04.025

9. Grigalevicius, S.; Ledeikis, E.; Grazulevicius, J. V.; Gaidelis, V.; Antulis, J.; Jankauskas, V.; Van, F. T.; Chevrot, C. Polymer 2002, 43, 5693. doi:10.1016/S0032-3861(02)00466-4

10. Xia, C.; Advincula, R. C. Macromolecules 2001, 34, 5854. doi:10.1021/ma002036h

11. Li, H.; Zhang, Y.; Hu, Y.; Ma, D.; Wang, L.; Jing, X.; Wang, F. Macromol. Chem. Phys. 2004, 205, 247. doi:10.1002/macp.200300037

12. Chen, J. P.; Natansohn, A. Macromolecules 1999, 32, 3171. doi:10.1021/ma981609b

13. Huang, J.; Niu, Y.; Yang, W.; Mo, Y.; Yuan, M.; Cao, Y. Macromolecules 2002, 35, 6080. doi:10.1021/ma0255130

14. Grigoras, M.; Antonoaia, N. C. Eur. Polym. J. 2005, 41, 1079. doi:10.1016/j.eurpolymj.2004.11.019

15. Liou, G. S.; Hsiao, H. S.; Chen, H. W. J. Mater. Chem. 2006, 16, 1831. doi:10.1039/b602133f

16. Fu, H. Y.; Wu, H. R.; Hou, X. Y.; Xiao, F.; Shao, B. X. Synth. Met 2006, 156, 809. doi:10.1016/j.synthmet.2006.04.013

17. Leclerc, M.; Michaud, A.; Blouin, N. Adv. Mater. 2007, 19, 2295. doi:10.1002/adma.200602496

18. Zou, Y.; Gendron, D.; Aich, R. B.; Najari, A.; Leclerc, M. Macromolecules 2009, 42, 2891. doi:10.1021/ma900364c

19. Aïch, R. B.; Blouin, N.; Bouchard, A.; Leclerc, M. Chem. Mater. 2009, 21, 751. doi:10.1021/cm8031175

20. Pan, X.; Liu, S.; Chan, H. S. O.; Ng, S. C. Macromolecules 2005, 38, 7629. doi:10.1021/ma050425b

21. Zheng, J.; Zhan, C.; Qin, J.; Zhan, R. Chem. Lett. 2002, 1222. doi:10.1246/cl.2002.1222

22. Jenekhe, S. A.; Lu, L.; Alam, M. M. Macromolecules 2001, 34, 7315. doi:10.1021/ma0100448

23. Beginn, C.; Gražulevičius, J. V.; Strohriegl, P.; Simmerer, J.; Haarer, D. Macromol. Chem. Phys. 1994, 195, 2353. doi:10.1002/macp.1994.021950706

24. He, Y.; Zhong, C.; He, A.; Zhou, Y.; Zhang, H. Mater. Chem. Phys. 2009, 114, 261. doi:10.1016/j.matchemphys.2008.09.020

25. Liu, Y.; Di, C.-a.; Xin, Y.; Yu, G.; Liu, Y.; He, Q.; Bai, F.; Xu, S.; Cao, S. Synth. Met. 2006, 156, 824. doi:10.1016/j.synthmet.2006.04.011

26. Zimmermann, E. K.; Stille, J. K. Macromolecules 1985, 18, 321. doi:10.1021/ma00145a003

27. Liaw, D.-J.; Wang, K.-L.; Chang, F.-C. Macromolecules 2007, 40, 3568. doi:10.1021/ma062546x

28. Zheng, J. Y.; Feng, X. M.; Bai, W. B.; Qin, J. G.; Zhan, C. M. Eur. Polym. J. 2005, 41, 2770. doi:10.1016/j.eurpolymj.2005.05.020
29. De Rossi, U.; Moll, J.; Kriwanek, J.; Daehne, S. J. Fluoresc. 1994, 4, 53. doi:10.1007/BF01876654

30. Koch, W.; Heitz, W. Makromol. Chem. 1983, 184, 779. doi:10.1002/macp.1983.021840412

31. Liu, S.; Jiang, P.; Song, G.; Liu, R.; Zhu, H. Dyes Pigm. 2009, 81, 218. doi:10.1016/j.dyepig.2008.10.010

\section{License and Terms}

This is an Open Access article under the terms of the Creative Commons Attribution License

(http://creativecommons.org/licenses/by/2.0), which permits unrestricted use, distribution, and reproduction in any medium, provided the original work is properly cited.

The license is subject to the Beilstein Journal of Organic Chemistry terms and conditions:

(http://www.beilstein-journals.org/bjoc)

The definitive version of this article is the electronic one which can be found at: doi:10.3762/bjoc. 7.75 